\title{
Comparative study between diarrheagenic Escherichia coli virotypes from Mexico City and San Luis Potosí
}

\author{
Ana M. Castro ${ }^{1 *}$, Carmen Mercado-Alquicira ${ }^{1}$, Ruth A. Cervantes-Olmos ${ }^{1}$ and Patricia Arzate-Barbosa ${ }^{2}$ \\ ${ }^{1}$ Department of Public Health, Faculty of Medicine, National Autonomous University of Mexico; ${ }^{2}$ National Institute of Pediatrics. Mexico City, Mexico
}

\begin{abstract}
The distribution and frequency of Escherichia coli virotypes can vary considerably from region to region, due to the geographical characteristics, the degree of social lag as well as the population of each region. Therefore, the objective of the present work was to compare Escherichia coli isolated from children with diarrhea obtained from two states with different levels of social lag and establish virotypes, adhesion to HEp-2 cells, biofilm formation, and antimicrobial resistance of this bacterium. In the present work, we compared E. coli isolated from children with diarrhea obtained from the City of San Luis Potosi (S.L.P.) with E. coli isolated from children with diarrhea of Mexico (City CDMX), with the purpose of identifying and establishing virotypes, adherence to HEp-2 cells, formation of biofilms, and antimicrobial resistance of these bacteria. The results showed that the percentage of virotypes found in S.L.P., were higher with respect to the virotypes found in the CDMX, being enterotoxigenic the most frequent virotype for both populations. The incidence of this virotype was higher for E. coli isolated from S.L.P., and the statistical analysis showed $p<0.000$. The incidence of the enteroinvasive and EHEC virotypes was higher in the state of S.L.P., with $p<0.000$. The adhesion phenotype, both aggregative and diffuse, was related to the presence of the aat and astA genes. The tests to determine the production of biofilms in strains of E. coli, allowed us to determine that the method in Congo red agar, were the most effective for its evaluation. In relation to the antimicrobials tested, a higher percentage of resistance of the E. coli strains of the CDMX was observed, in relation to the strains of S.L.P., with a statistically significant difference of $p<0.05$.
\end{abstract}

Key words: Comparative study. Diarrheagenic Escherichia coli. Children. Virotypes. Antimicrobial resistance.

\section{Introduction}

Changes in society, technology, and microorganisms alone contribute to the emergence of new diseases, to the re-emergence of already controlled diseases, as well as to the development of antimicrobial resistance. At present, pathogens resistant to several antimicrobials have proliferated, both in humans and in veterinary medicine.

Gastrointestinal diseases in infants are one of the public health problems worldwide, especially in developing countries such as Mexico.
In 2015, the World Health Organization estimated that diarrheal diseases cause more than half of the global burden of foodborne diseases, with 550 million people sick and 230,000 people dying every year. Diarrhea is usually due to the ingestion of poorly cooked foods or dairy products contaminated with norovirus, Campylobacter, nontyphoidal Salmonella, and pathogenic Escherichia coli ${ }^{1}$. In Mexico, intestinal infections represented the second cause of morbidity, with more than five million cases in 2011, which placed

\section{Correspondence:}

*Ana M. Castro

E-mail: amcastro@unam.mx
Available online: 30-07-2019
Date of reception: 16-02-2018

Date of acceptance: 24-05-2018

DOI: 10.24875/HGMX.M19000022
Rev Med Hosp Gen Mex. 2019;82(2):67-77 www.hospitalgeneral.mx
0185-1063/@ 2018 Sociedad Médica del Hospital General de Mexico. Published by Permanyer México SA de CV. This is an open access article under the CC BY-NC-ND license (http://creativecommons.org/licenses/by-nc-nd/4.0/). 
this condition as an important public health problem, since the national incidence increased for the third consecutive year, with the most vulnerable sector being children under 5 years of age ${ }^{2}$.

In 2013, acute diarrheal disease (ADD) was the second cause of morbidity in the population under 5 years of age in the state of San Luis Potosi (S.L.P.), where the disease can present serious complications in children, due to some circumstances such as having a birth weight of $<2.5$ kilos, have not received breastfeeding, have some degree of malnutrition, and do not have the complete vaccination schedule according to their age $^{3}$. In 2013, the number of children under 5 years with ADD was approximately 40 thousand cas$\mathrm{es}^{4}$. The incidence of ADD in this state may be due to the social backwardness, since according to the National Council for the Evaluation of Social Development Policy (CONEVAL) in the year 2012, SLP occupied tenth place in social backwardness at the national level, while Mexico City was located at 31 places, with a very low degree of social lag ${ }^{5}$.

Among the virulence factors of $E$. coli are adhesins and toxins. Pathogenic strains of $E$. coli have specific adhesion factors ${ }^{6}$, which allow them to colonize the intestine. These adhesions can be divided into two groups: fimbrial adhesins and afimbrial adhesins ${ }^{7}$. The afimbrial adhesins are outer membrane proteins such as intimin 6 .

Bacterial toxins are of two types, lipopolysaccharide endotoxins and exotoxins. Exotoxins are classified as enterotoxins, cytotoxins, and neurotoxins. Enterotoxins produce watery diarrhea and inflammatory diarrhea cytotoxins, whose bowel movements contain blood and mucus $^{7}$. Once $E$. coli has colonized the intestine, the damage is caused by the production of enterotoxins, cytotoxins as well as by invasion of the target cell.

Based on their mechanism of damage, E. coli are classified into six pathotypes: Enterotoxigenic (ETEC), Enterohemorrhagic, also known as producers of STx toxin (EHEC), Enteropathogenic E. coli (EPEC) is classified in tEPEC (they have the bfpA + genes) eaeA) and aEPEC (possesses the eaeA gene), Enteroaggregative E. coli (EAEC), enteroinvasive (EIEC), and diffuse adherence E. coli ${ }^{6}$.

Savarino et al. ${ }^{8}$ have considered the astA gene, which codes for the EAST1 enterotoxin, as a characteristic of the EAEC group. On the other hand, Nataro et al. ${ }^{9}$ recognized two different phenotypes of $E$. coli, belonging to the enteroadherent strain: diffuse and enteroaggregative, this discovery is the first description of EAEC. The enteroaggregative adhesion is characterized by a formation of "stacked brick" (stacked-brick in English), where bacteria adhere to both the cell surface and the glass of the preparation. The reproducibility presented by this trial has made it a standard test for the determination of the aggregative adhesion phenotype and thus the identification of the EAEC virotype. In addition to, molecular assays such as the production of the EAST1 toxin, encoded by the astA gene ${ }^{8}$, the aat gene, which codes for a protein called dispersion, as well as the chromosomal gene AggR present in a pathogenicity island of $E$. coli was identified ${ }^{10}$.

In nature, microorganisms rarely live in isolated colonies of a single species, generally, living in communities called biofilms ${ }^{11}$. Biofilm is a term used to define biological systems or a matrix with bacterial populations adhered to each other and/or to a surface. This structure allows bacteria to take refuge from harmful factors such as the environment, antibiotics, and immune system, among others ${ }^{11}$.

The architecture is not solid, on the inside microcolonies are communicated by microchannels that favor the entry of nutrients and elimination of waste products ${ }^{12}$.

Recently, it was found that the moment when E. coli begins to form the biofilm, the bacteria become ovoid and smaller to eventually enter a stationary phase where they stop dividing. As this occurs, they begin to produce and excrete autoaggregation curli fibers. These curli fibers, at the molecular level, are proteins assembled in an amyloid structure, which allows their staining with Congo Red ${ }^{13}$.

The presence of biofilm produced by $E$. coli had been considered a very important virulence factor since it has been related to antimicrobial resistance. The formation of this structure was detected in catheters, medical instruments and heart valves, favoring the chronicity of the ailments and making their elimination difficult ${ }^{13}$.

For the study of the biofilm production of different microorganisms, several methodologies have been developed, among them are the Christensen Tube Method and the Congo Red in agar plates. Christensen et al. ${ }^{14}$ were recognized one of the first groups to develop methodologies to determine the production of biofilm. When conducting various investigations of intrahospital infections, they found a certain mucoid substance in catheters, heart valves, and prostheses, among others and were associated with infections caused by coagulase-negative staphylococci (usually Staphylococcus epidermidis) that produce what they called at that time, slime.

Ensuring that the Christensen method is not always successful in determining biofilm production and that variations in the culture medium affect the results, 
Freeman et al. ${ }^{15}$ described an alternative methodology to detect the production of biofilm on a solid medium. This method is based on the coloration of the bacterial colonies, thanks to the Congo red dye present in the brain-heart infusion agar plates.

In both Latin America and North America, epidemiological studies were conducted and the purpose was to determine different pathotypes associated with diarrhea cases in children. These studies demonstrated that E. coli that belongs to the ETEC and EPEC pathotypes are the main isolated pathogens ${ }^{15-17}$. In regard to Mexico, since 1987, several studies showed the presence of EPEC in most of the isolates obtained from patients with a prevalence of $17-19 \%$ of cases of infant diarrhea ${ }^{18}$. In 2005, Estrada et al. reported the presence of four E. coli pathotypes in a community bordering Mexico City.

On the other hand, despite the efforts made for the prevention and control of infectious diseases, they continue to represent a global public health problem due to both emerging and re-emerging microorganisms.

Among the pathogens that are emerging and resistant to antimicrobials are $E$. coli, which affects humans and different animal species. Multiple investigations in both humans and animals show resistance to the most frequently used antimicrobials ${ }^{19-22}$. Bacteria are generally resistant to more than one antimicrobial ${ }^{21}$. Studies in Mexican children show that these bacteria cause diarrhea disease in hospitalized children and are resistant to trimethoprim-sulfamethoxazole (TMP-SMX) and ampicillin (AM). These drugs are mostly used in the treatment of pediatric diarrhea ${ }^{17}$. In the State of S.L.P., there are no studies in this regard.

For the aforementioned, the objective of the present work was to compare the $E$. coli isolated from children with diarrhea obtained from two states with different degree of social lag and establish the virotypes, adhesion to HEp-2 cells, biofilm formation and antimicrobial resistance of said bacteria.

\section{Materials and methods}

\section{Bacterial strains and characterization}

The study was conducted from 38 stool samples from children with diarrhea from the Dr. Ignacio Morones Prieto Central Hospital in the state of SLP and 27 stool samples from children from the National Institute of Pediatrics (INP) of Mexico City. The samples were taken by highly qualified personnel; later they were transported to the laboratory in the Cary Blair medium. Once in
Table 1. Percentage of genes found in E. coli strains from each population studied

\begin{tabular}{|l|c|c|}
\hline${ }^{1}$ Genes & $\begin{array}{c}\% \text { of Strains } \\
\text { Mexico City }\end{array}$ & $\begin{array}{c}\% \text { of Strains } \\
\text { S.L.P. }\end{array}$ \\
\hline$L T^{*}$ & 30 & 57 \\
\hline$S T^{*}$ & 14 & 37 \\
\hline$S T: L T^{*}$ & 2 & 27 \\
\hline$i a l^{*}$ & 4 & 28 \\
\hline St $\times 1^{*}$ & 3 & 22 \\
\hline St $\times 2$ & 0 & 9 \\
\hline$S t \times 1: S t \times 2$ & 0 & 5 \\
\hline$S t \times 1: S t \times 2: e a e A$ & 4 & 0 \\
\hline$e a e A$ & 9 & 9 \\
\hline$b f p A$ & 2 & 0 \\
\hline astA & 14 & 13 \\
\hline aat & 3 & 1 \\
\hline astA:aat & 3 & 0 \\
\hline
\end{tabular}

Genes that code for: $L T$ : heat-labile toxin; $S T$ : heat-stable toxin; $S t \times 1$ and St $\times 2$ : "Shiga-like" cytotoxins; eaeA: gene that codes for intimina; bfpA: codifies for pili hair formers; ial: invasiveness; astA: enteroaggregative toxin heat stable EAST1; aat gene that participates in the secretion of the protein called dispersin. ${ }^{*} \mathrm{p}<0.05$; S.L.P.: San Luis Potosí.

the laboratory, they were planted on MacConkey agar medium (DIBICO ${ }^{\circledR}$ ) and incubated at $37^{\circ} \mathrm{C}$ for $24 \mathrm{~h}$. One to five colonies were selected, with morphological characteristics of E. coli. Subsequently, conventional biotyping tests were performed to confirm the presence of E. coli. From these tests, 100 strains of $E$. coli from S.L.P. and 100 strains of E. coli from Mexico City were obtained. In addition to these biochemical tests, the production of $\beta$ hemolysis was evaluated. To do this, the strains of $E$. coli were seeded on $5 \%$ sheep blood agar, incubated at $37^{\circ} \mathrm{C}$ for $24 \mathrm{~h}$ and subsequently the $\beta$ hemolysis was evaluated by observing the total destruction of the erythrocytes. Reference strains A panel of $E$. coli reference strains were used as positive controls for the different polymerase chain reaction (PCR) assays, antibiograms, and adhesion to HEp-2 cells. Strains TB334C (Stx1 +, Stx2 +, eaeA +), B-171 (BfpA +, eaeA +), EIEC O124: H30 (ial +), and O407: H1 (LT +, ST + ) were kindly donated by Dr. Estrada García of the Research Center and Advanced Studies (CINVESTAV), EAEC 044: H18 (aat, astA) strain donated by Dr. Chattaway of Public Health England. Finally, $\mathrm{O} 42$ and $\mathrm{C600}$ (K12) strains were provided by the National Epidemiological Reference Institute of Mexico (INDRE). 


\section{DNA extraction and PCR reaction}

The genomic DNA of the $E$. coli isolates was extracted by the boiling method, previously described by Al-Gallas et al. ${ }^{23}$. The PCR (single or multiple) allowed to detect genes that code for the toxins (LT, STa, Stx1, Stx2, and EAST1) and genes that code for adhesins (intimina, eae, pili Type IV, bfpA, for invasiveness and gene that codes for dispersin, aat). The PCR reactions used for the amplification of the different genes were carried out using Apex Taq DNA polymerase (Genesee Scientific, USA) and primers. The $50 \mu \mathrm{l}$ reaction mixtures contained the following: $1 \mathrm{X}$ buffer $(100 \mathrm{mM}$ Tris- $\mathrm{HCl}, \mathrm{pH} 8.5$, $500 \mathrm{mM} \mathrm{KCl}, 15 \mathrm{mM} \mathrm{MgCl} 2,1 \%$ Triton X-100), $0.2 \mathrm{mM}$ of each dNTP (Apex dNTP mixture, $10 \mathrm{mM}$ ), $0.25 \mu \mathrm{M}$ of each primer, $2.0 \mathrm{U}$ of Apex Taq DNA polymerase, 3 $\mu \mathrm{l}$ of tempered DNA, and $37 \mu \mathrm{l}$ of nuclease-free water. The multiplex PCR products ( $\mathrm{MPCR}$ ) were separated on a $2 \%$ Agarose gel (Amresco, Ohio, USA). The amplified $\mathrm{PCR}$ products were visualized with ethidium bromide under a UV illuminator and recorded using the Digidoc Imaging System (UVP, CA, U.S.A.).

\section{Antimicrobial susceptibility assays}

The antimicrobial susceptibility test was carried out to determine the profiles of susceptibility and resistance of the bacteria to the antibiotics tested. For this, the paper disc diffusion method was used. Impregnated antimicrobial discs with AM (10 mu.g), amikacin $(30 \mu \mathrm{g})$, kanamycin $(30 \mu \mathrm{g})$, cephalothin $(30 \mu \mathrm{g})$, amoxicillin/ clavulanate $(30 \mu \mathrm{g})$, cefotaxime $(30 \mu \mathrm{g})$, TMP/SMX $(1.25 \mathrm{mu} . \mathrm{g} / 23.75 \mu \mathrm{g})$, and cefoxitin $(30 / \mathrm{mg})$. These discs (6 $\mu \mathrm{m}$ diameter) were placed in an automatic Sensi Disc dispenser (DB BBL Sensi Disc Antimicrobial Susceptibility Test Discs, Sparks MD, USA). The inoculated agar plates were incubated at $37^{\circ} \mathrm{C}$ for $18-24 \mathrm{~h}$. After incubation, the diameters of the zone of inhibition of the antibiotic were measured. The results were used to classify the isolates as resistant, intermediate, or susceptible to a particular antibiotic, using standard reference values as shown in the National Committee for Clinical Laboratory Standards 2014. Multidrug resistance defined as resistance to three or more different classes of antibiotics.

\section{Adhesion test in HEp-2 cells}

One hundred strains of $E$. coli previously identified as EAEC (ast1 + and/or aat +) were tested for adhesion to HEp-2 cells, as described by Donnenberg and
Nataro ${ }^{24}$, with modifications. In summary, $6.0 \times 105$ HEp-2 cells were cultured in DMEM medium with high glucose content (Biowest, Miami FL, USA) supplemented with $10 \%$ fetal bovine serum (Biowest, Miami FL, USA) and $1 \%$ antibiotic/antifungal solution (PAA, Pasching, Austria). The cells were placed in 24-well plates (TPP, Switzerland) containing a glass lentil and incubated until reaching a confluence of $80-90 \%$ (1-2 days). The HEp-2 cells were washed 3 times with sterile PBS, $500 \mu \mathrm{l}$ of fresh DMEM medium without fetal bovine serum or antibiotics were added.

One day before the experiment, the $E$. coli strains were grown overnight in $1.5 \mathrm{ml}$ of LB medium with $1 \%$ D-mannose and the concentration was adjusted to 0.5 UMF $(2 \times 108 \mathrm{CFU} / \mathrm{ml})$ with sterile PBS. The cultures were centrifuged and then resuspended in $1 \mathrm{ml}$ of sterile PBS. $50 \mu$ of the bacterial suspension was mixed with $450 \mu \mathrm{l}$ of DMEM medium without fetal bovine serum or antibiotics and inoculated into cultures of HEp2 cells. The infected cells were incubated for $3 \mathrm{~h}$ at $37^{\circ} \mathrm{C}$ under a $5 \% \mathrm{CO}_{2}$ atmosphere and washed 5 times with sterile PBS, fixed with absolute methanol for $1 \mathrm{~min}$ and stained with $10 \%$ Giemsa. Adherence patterns were assigned according to the description of Nataro and Kaper ${ }^{6}$.

Controls in each experiment included strains of E. coli $\mathrm{O} 42$ that showed aggregate adhesion and $E$. coli K12 that did not bind to HEp-2 cells.

\section{Results}

The present study was carried out with 200 strains of $E$. coli, 100 of them from the Central Hospital Dr. Ignacio Morones Prieto of the state of S.L.P., and 100 from the INP, from the Mexico city.

The $\beta$-hemolysis assay showed that of the 200 strains of $E$. coli studied, 25 had $\beta$-hemolysis, of which 14 were from Mexico city and 11 from S.L.P.

\section{Identification of virulence genes of E. coli}

Through the PCR assay, nine virulence genes were identified, of which five code for toxins (LT, ST, STX1, STX2, and astA), two for adhesins (bfpA and eaeA), one for invasiveness (ial), and a gene that participates in the secretion of the protein called dispersin, aat.

As can be seen in Table 1, of the strains of $E$. coli isolated from the Mexico city, $30 \%$ presented the LT gene; $14 \%$ the ST gene, $14 \%$ the astA gene, and $4 \%$ the ial gene. While for the state of S.L.P., $57 \%$ of the strains presented the LT gene; $37 \%$ presented TS; $27 \%$ 
Table 2. Type of adherence and genes that carry strains of $E$. coli

\begin{tabular}{|l|c|l|c|c|c|}
\hline Location & $\begin{array}{c}\text { Number of } \\
\text { strains }\end{array}$ & Genes & \multicolumn{3}{|c|}{ Type of adherence } \\
\hline CDMX & 14 & astA+ & 1 & 10 & 3 \\
\hline & 0 & aat+ & 0 & 0 & 0 \\
\hline Total & 3 & astA+:aat+ & 0 & 2 & 1 \\
\hline Strains & 17 & & & & \\
\hline S.L.P. & 13 & astA+ & 4 & 4 & 5 \\
\hline & 1 & aat+ & 0 & 0 & 1 \\
\hline Total & 14 & astA+:aat+ & 0 & 0 & 0 \\
\hline strains & 0 & & & & \\
\hline
\end{tabular}

AA: aggregate adherence; AD: diffuse adhesion; N: negative adhesion; S.L.P.: San Luis Potosí.

presented the LT: ST genes; $28 \%$ presented the ial gene, $22 \%$ presented the STX1 gene, $13 \%$ the antler gene, and $9 \%$ presented the eaeA gene. These being the most prevalent among the nine genes studied. The statistical analysis showed significant differences $(p<0.05)$ for the LT, ST, LT: ST, ial, and STX1 genes.

\section{Virotypes}

The identification of virulence genes allowed us to classify $E$. coli into virotypes. This classification was made according to what was published by Estrada-García et al. ${ }^{17}$ (Fig. 1) and obtained the following results. For Mexico City: ETEC was $49 \%$ and in SLP was $67 \%$. The statistical analysis showed a significant difference with a $p=0.009$. EAEC in Mexico City was presented in $14 \%$ and in S.L.P. was $14 \%$. EIEC in Mexico City with $4 \%$ and in S.L.P. was $28 \%$, and the statistical analysis showed a significant difference of $p=0.000$. EHEC for Mexico City with $3 \%$ and in S.L.P. was $30 \%$, and the statistical analysis showed a significant difference with a $p=0.000$. The percentage of strains that were aEPEC in Mexico City was $9 \%$ and for S.L.P. was $5 \%$.

\section{Adherence assay to HEp-2 cells}

Adherence is one of the first factors for pathogenic $E$. coli strains to cause diarrheal infections. For this purpose, a gold standard test was considered for the identification of the EAEC virotype. This test consists of adherence of the bacteria to a monolayer of HEp-2 cells.

As can be seen in table 2, of the 17 strains of E. coli that were evaluated for Mexico City, only one strain presented aggregative adherence (AA) and it was ast $A+$. Twelfth strains showed diffuse adherence (AD) and of which two presented both ast $A$ and aat genes. The remaining four strains did not present any adherence pattern. Patterns of adherence of $E$. coli to HEp-2 cells (Fig. 2). Figure 2A shows negative control of adhesion of $E$. coli and we used the strain K-12. Figure $2 \mathrm{~B}$ shows the positive control of aggregate adhesion and we used the strain O:42. Figures $2 \mathrm{C}, \mathrm{D}, \mathrm{E}$ and $\mathrm{F}$, show different patterns of adherence, these strains of E. coli were isolated of samples from the CDMX and S.L.P.; C) shows diffuse adherence, the $E$. coli strain comes from S.L.P.; E) Shows aggregative adherence, the E. coli strain comes from the CDMX; F) shows aggregative adherence and the $E$. coli strain comes from S.L.P.

For S.L.P., 13 strains presented the astA gene of which four presented $A A$, four presented $A D$, and five strains did not present adherence. Regarding the strain that possesses the aat gene, it did not show adherence (Table 2).

\section{Biofilm production}

To evaluate the biofilm production, the Congo red and Christensen agar assays were used for which the strains that showed mobility were taken into account. Of the E. coli isolated from the CDMX, $60 \%$ were mobile and $84 \%$ for S.L.P.

\section{Congo red agar assay}

Of the 60 strains of flagellated $E$. coli isolated from the CDMX, only 42 strains formed biofilm and of which 11 were strong producers of biofilm $(++), 31$ were considered weak producers of the biofilm (+), and 18 strains were negative. For SLP, of the 84 strains of flagellated E. coli, only 64 strains formed biofilm, of these 28 were strong producers $(++)$, and 36 strains were weak producers of biofilm $(+)$, and 20 of them were negative (Table 3). In figure 3 , the staining acquired by the colonies when producing biofilm is observed.

\section{Christensen method (tube method)}

According to the Christensen method, of 60 flagellate strains of $E$. coli for CDMX, 11 strains were biofilm 


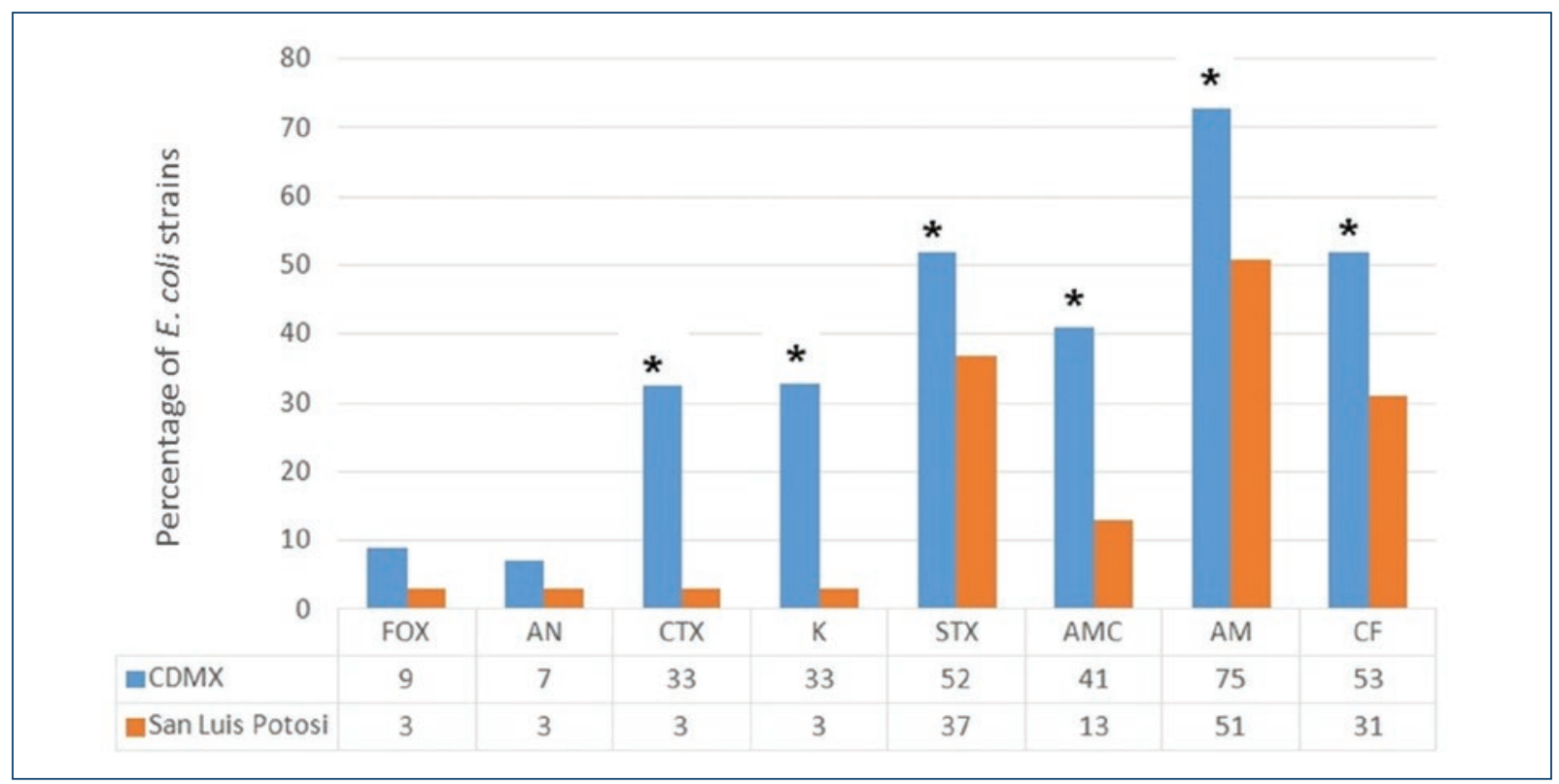

Figure 1. Cefoxitin, amikacin, cefotaxime, kanamycin, sulfamethoxazole/trimethoprim, amoxicillin/clavulanic acid, Ampicillin, cefalotin. ${ }^{*} p<0.00$.

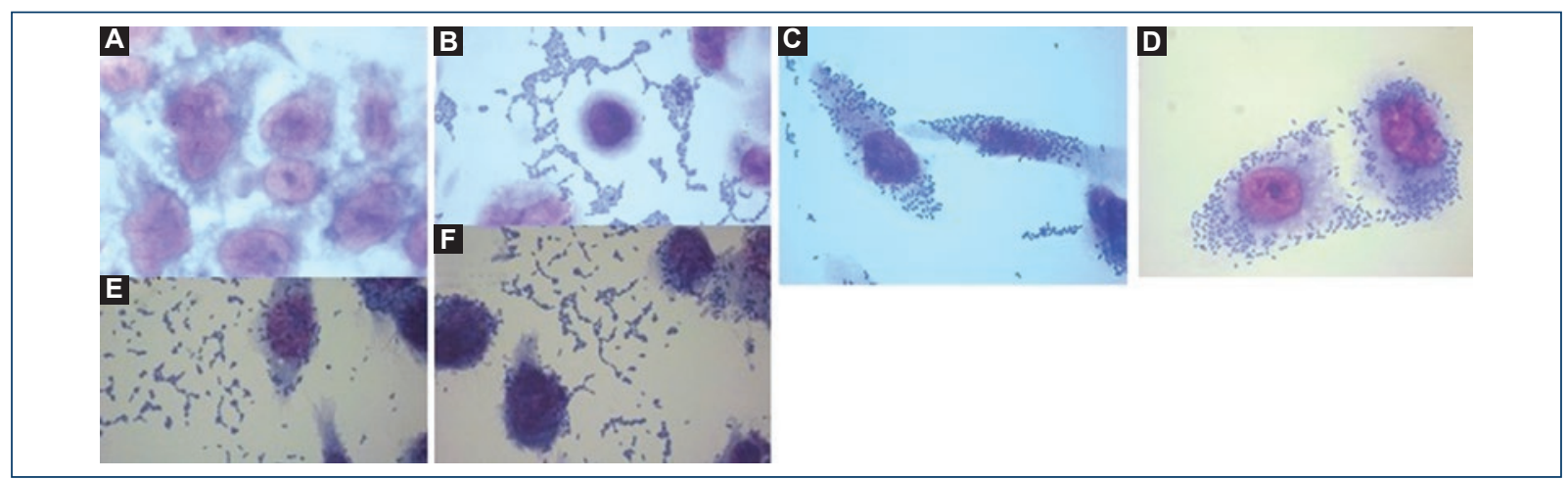

Figure 2. A: Negative control Escherichia coli strain K:12 ×100; B: Positive control aggregate adhesion strain E. coli 0:42 ×100; C: Diffuse adhesion strain $\times 100$ Mexico City; D: Diffuse adhesion strain $\times 100$ San Luis Potosi (S.L.P.); E: Aggregates adhesion strain $\times 100$ Mexico City; F: Aggregates adherence strain $\times 100$ S.L.P.

Table 3. Biofilm evaluation of $E$. coli strains by the Congo red agar method (ARC)

\begin{tabular}{|l|c|c|}
\hline \multirow{2}{*}{} & Red agar & Congo \\
\cline { 2 - 3 } & CDMX n (\%) & S.L.P. n (\%) \\
\hline$(++)^{1}$ & $11(19)$ & $28(33)$ \\
\hline$(+)^{1}$ & $31(51)$ & $36(43)$ \\
\hline Total positive strains & $42(70)$ & $64(76)$ \\
\hline$(-)^{1}$ Total negative strains & $18(30)$ & $20(24)$ \\
\hline Total strains evaluated & $60(100)$ & $84(100)$ \\
\hline
\end{tabular}

${ }^{1}(++)$ strong biofilm-producing strains, $(+)$ weak biofilm-producing strains. (-) non-biofilm-producing strains. S.L.P.: San Luis Potosí. producers, while for S.L.P. of 84 flagellate strains of $E$. coli, 18 strains were biofilm producers. The number of strains that were not biofilm producers for CDMX was 48 strains and 66 strains for S.L.P. (Table 3). Figure 4 shows the staining of the tube wall inoculated with a biofilm-producing strain.

\section{Antibiogram}

To evaluate the resistance and sensitivity to certain antibiotics, antibiogram tests were performed. As we can see in figure 5 , the strains of $E$. coli isolated from Mexico City showed $75 \%$ resistance to 


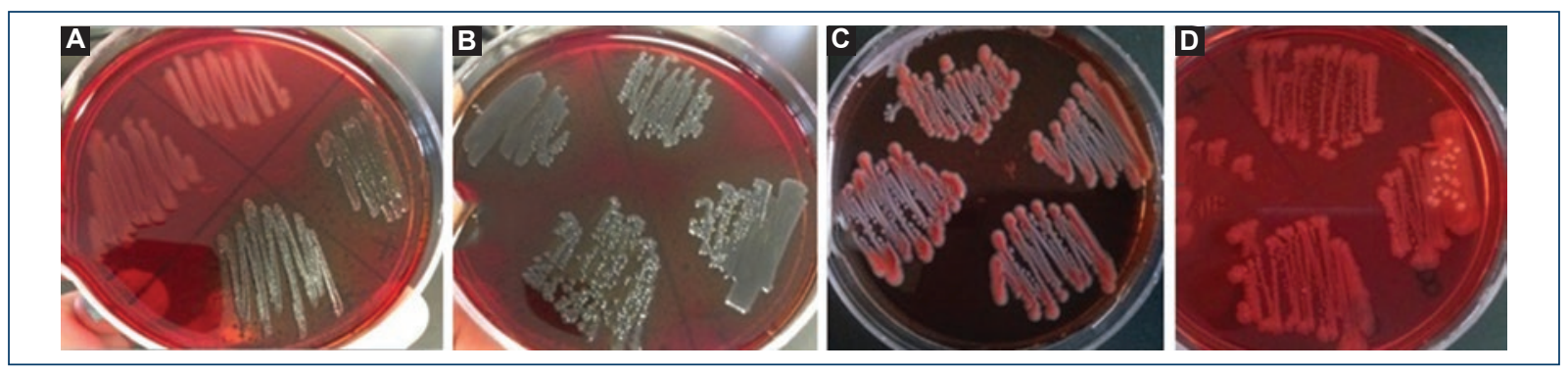

Figure 3. A: Upper strain 0:42 negative control (colorless colonies), lower part K strain: 12 positive control (crystalline dry black colonies); B: $(++)$ dry black crystalline colonies; C: Pink colonies with the black center $(+)$; D: Colorless colonies, negative control; (B-D) Belong to strains of San Luis Potosi.

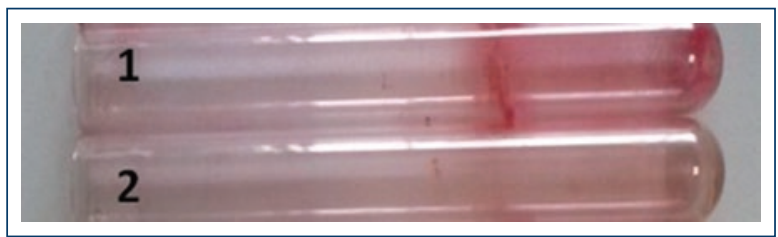

Figure 4. Tube 1, Escherichia coli K12 positive control strain. Tube $2(-), 0: 42$ negative control strain.

AM, while the strains from SLP showed $51 \%$ and the statistical analysis showed a statistically significant difference with $p=0.000$. About $53 \%$ of the strains of Mexico City were resistant to cefalotin (CF) and in S.L.P., only $31 \%$ with $p=0.001$. About $52 \%$ of the Mexico City strains showed resistance to SMX/TMP in relation to $37 \%$ of strains of S.L.P. with $p=0.03$. $41 \%$ of the strains of Mexico City showed resistance to amoxicillin/Clavulanic acid in relation to $13 \%$ of strains of S.L.P. with a statistically significant difference of $p=0.000$. About $33 \%$ of the strains were resistant to kanamycin in Mexico City, in relation to $3 \%$ of the strains of SLP and the statistical analysis showed $p=0.000 .33 \%$ strains in the CDMX and $3 \%$ in SLP presented resistance to cefotaxime, with $p=0.000$.

\section{Discussion}

The bacterium E. coli is the etiological agent of diseases of the digestive tract, urinary tract, and central nervous system. At present, it is known that there are several factors related to genotypic changes of this bacterium, from which derives the importance of determining not only the bacterium as the causative agent of diarrhea but also to identify the virulence genes related to the disease.
Although there are reports in which the prevalence of different pathotypes was determined, these studies come from populations from different geographical areas, different development conditions and different age groups, which makes it difficult to carry out comparative studies.

In the present work, to compare the $E$. coli virotypes from two states of the Mexican Republic and evaluate both genotype and phenotype, stool samples were obtained from children with diarrhea from SLP and Mexico City. The population are different both in geographical characteristics and in their population composition. According to data obtained from the National Institute of Statistics and Geography (INEGI), 36\% of the population in SLP and only $0.5 \%$ in Mexico City are considered rural and with differences in the degree of social lag.

The results showed a higher incidence of $E$. coli virotypes isolated from stool samples from S.L.P. in relation to the virotypes of this bacterium identified from Mexico City.

The virotype that presented a higher prevalence in both study groups was ETEC. In Mexico City $49 \%$ and S.L.P. About $67 \%$ of the strains and the statistical anal$y$ sis showed a significant difference $(p=0.009)$. The data obtained in this work agree with that published by Nataro and Kaper ${ }^{6}$ Paniagua et al. ${ }^{3}$ and Qadri et al. ${ }^{25}$ who affirm that ETEC is the most frequently found pathotype in developing countries as well as in developed countries, and the high prevalence of ETEC is related to its capacity for colonization ${ }^{6}$.

Regarding the virulence genes identified for ETEC, the genes that code for LT and ST toxins were those that occurred most frequently in the strains studied. The prevalent gene for both groups was the one that codes for the LT toxin. The strains isolated from Mexico City presented $30 \%$ and SLP $57 \%$ of the strains. This 


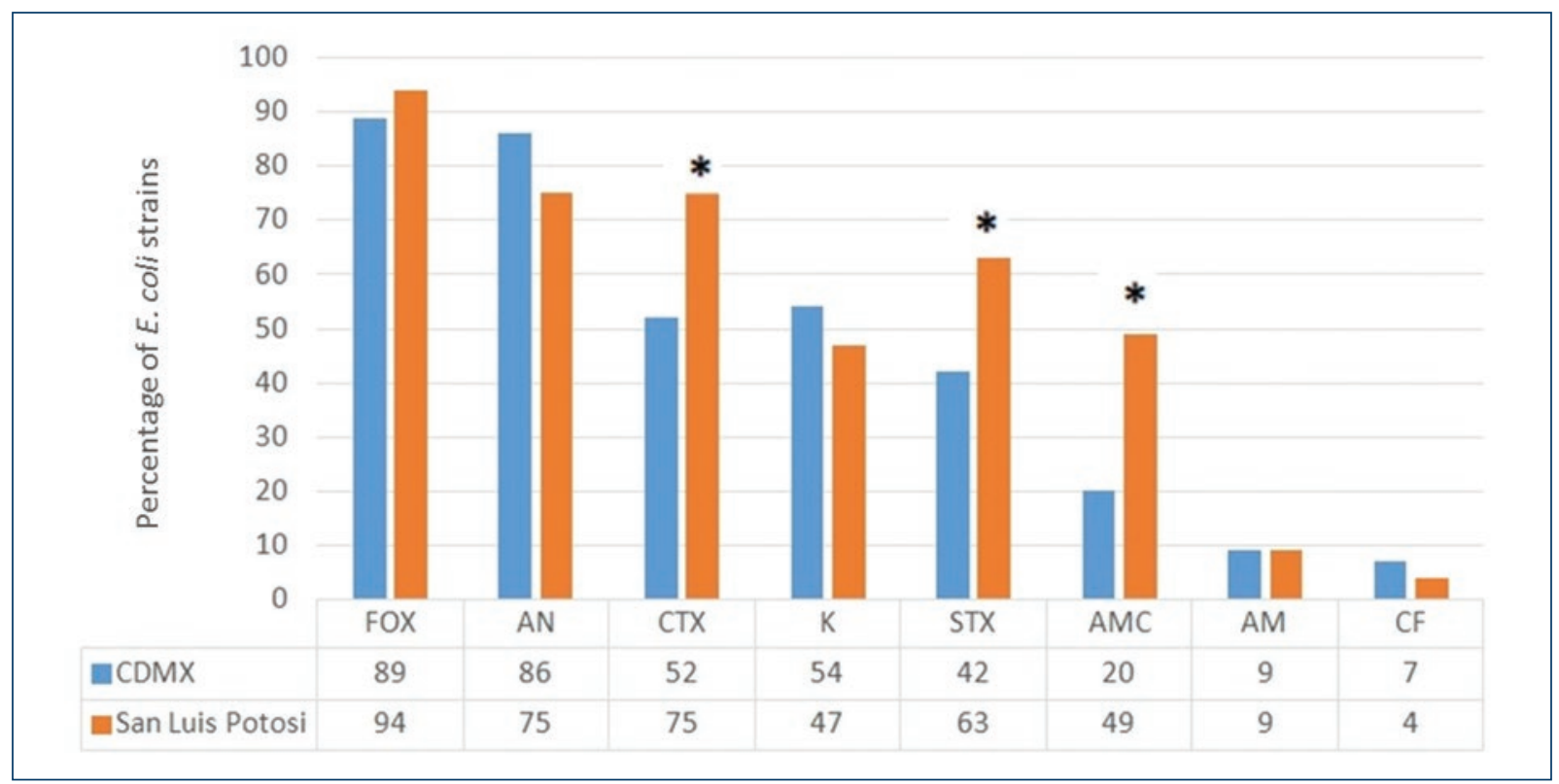

Figure 5. AM: ampicillin; AMC: amoxicillin/clavulanic acid; AN:amikacin; CF: cefalotin; CTX: cefotaxime; FOX: cefoxitin; K: kanamycin; STX: sulfamethoxazole/trimethoprim. ${ }^{*} p<0.00$.

is concordant with Cortes et al. ${ }^{26}$, Jiang et al. ${ }^{27}$, Paniagua et al. ${ }^{3}$, Estrada-García et al. ${ }^{28}$, and Qadri et al. ${ }^{25}$.

Given that, E. coli strains were from fecal samples taken during the spring and summer seasons, it is likely that the incidence of the ETEC pathotype is seasonal, and this is in line with that published by Estrada-García et al. ${ }^{28}$.

The EHEC virotype was the second most frequent in the state of S.L.P., with $30 \%$ of the positive strains and in the CDMX with $3 \%$. The statistical analysis showed a significant difference $(p=0.000)$. The high prevalence of this virotype in the S.L.P. population is striking compared to both Mexico City and that published by other authors. Estrada-García et al. ${ }^{28}$ showed that the frequency of EHEC in Mexico City was 2.5\%. Vilchez et al. ${ }^{29}$ in a study conducted in Nicaragua reported $2.1 \%$, Nataro and Kaper ${ }^{6}$ mentioned that this virotype is isolated less frequently in the underdeveloped population compared to the ETEC and EPEC virotypes. However, according to Clarke et al. ${ }^{30}$, EHEC has become an important virotype due to the increase in the number of outbreaks that have appeared in both developed and developing countries and mentions that this increase may be due to the high consumption of badly cooked food.

Despite the high prevalence of EHEC in S.L.P., there is no report from the health authorities of the state regarding the outbreaks of hemolytic uremic syndrome, as occurred in Germany in the year $2011^{31}$.
Like EHEC, the prevalence of the EIEC virotype was higher in the state of S.L.P. (28\%) and for Mexico City (4\%) finding a statistically significant difference $(p=0.000)$. Estrada García et al. ${ }^{28}$ found $5 \%$ of this virotype, which coincides with our data in Mexico City and differs with the results obtained in S.L.P.

Clarke et al. ${ }^{30}$ as well as Escher et al..$^{32}$ considered the EIEC virotype as the causal agent of morbidity and mortality in both children from developed and developing countries due to poor sanitary and hygiene conditions. It is likely that the high prevalence of this virotype in S.L.P. is related to that published by Clarke et al ${ }^{30}$ given that S.L.P. presents a high degree of social lag.

The EPEC virotype was presented in $9 \%$ of Mexico City and $5 \%$ of SLP strains. Paniagua, et $\mathrm{al}^{3}$., in a study in children with diarrhea in Mexico City determined the presence of EPEC with a percentage of $9.3 \%$ similar to that found in this work and to that of other countries, which ranges from 5 to $10 \%^{33}$. The EPEC virotype is classified as typical (tEPEC) and atypical (aEPEC). According to the results obtained in this study, only aEPEC strains were identified for both study groups, and these results coincide with what was published by Ochoa et al. ${ }^{34}$ who affirms that aEPEC is the most commonly associated virotype of diarrhea in children.

The EAEC virotype was found in $14 \%$ of the strains for both study groups, data similar to that published by Aslani et al. ${ }^{35}$ who conducted a study to identify the EAEC virotype in samples of children with diarrhea 
presenting in $10 \%$ of the study population ${ }^{36}$. Jenkins et al., (2006) out of 500 total samples were able to identify $8 \%$ of EAEC.

It has been considered that EAEC is an emergent pathotype $^{37}$ given that it has been presented in both developing and developed countries as in the case of the United Kingdom ${ }^{37}$. Furthermore, this pathotype has been associated as one of the causative agents of traveler's diarrhea ${ }^{29}$.

The genes identified for this virotype were aat and ast $A$, which have been related to the aggregative adhesion phenotype. The astA gene found in greater numbers with respect to the aat gene, in both study groups, which agrees with that published by Jenkins et al. ${ }^{36}$

Once these genes were identified, the adherence test was performed to evaluate the AA in E. coli strains. In Mexico City, of 17 strains that carried some of the two genes, only one strain showed AA and 12 diffuse adhesion strains. While for S.L.P., of 14 strains evaluated, four strains showed diffuse adherence and four strains AA. It should be mentioned that all the strains that had some type of adherence carried the ast $A$ gene. These data show that the ast $A$ and aat genes are present in $E$. coli strains with a not only aggregative adhesion phenotype but are also present in strains of $E$. coli that adhere to the HEp-2 cells in a diffuse form. These data agree with that published by Jenkins et al. ${ }^{36}$, who performed the HEp-2 cell adhesion assay and found no relationship between the presence of genes and the aggregative adhesion phenotype.

In relation to the higher prevalence of $E$. coli virotypes in SLP, compared to the E. coli virotypes identified in the CDMX, this may be due to the living conditions of the population belonging to a former state. According to INEGI, SLP is considered one of the states with the greatest social backwardness, since 53 of the $58 \mathrm{mu}$ nicipalities have a high degree of poverty such as lack of services, education, health, basic services, and spaces deficient housing. This favors that gastrointestinal diseases are a serious health problem for this population.

Another factor of virulence that has recently been considered of great clinical importance has been the production of biofilm in various bacteria, including E. coli $i^{12}$. In the present work, biofilm production was evaluated only in the mobile $E$. coli strains based on the work of Pratt and Kolter ${ }^{11}$, Reisner et al. ${ }^{12}$, and Wood et al. ${ }^{38}$ who showed that the flagellum is related to biofilm formation. The formation of this was evaluated by two methods: Congo red agar (ARC) and the Christensen method (in tube). By the Congo red method in Mexico City, $70 \%$ of the strains were biofilm producers and for S.L.P. $76 \%$ with the Christensen method, for Mexico City, $19 \%$ of the strains formed biofilm and for S.L.P. $21 \%$. The results obtained showed that, although all the strains evaluated showed mobility, not all of them were biofilm producers. This is why we consider that in addition to the flagellum, there are other factors that are related to the formation of said structure. Other factors related to biofilm formation include cellulose production ${ }^{39}$, as well as the expression of pili Type 1, which has been considered a determining factor in the first steps in biofilm production ${ }^{40}$.

The results showed that the most effective method to evaluate biofilm production was the ARC method. These data agree with that published by Serra et al..$^{13}$ Among the advantages of biofilm formation are resistance by bacteria to environmental conditions, evading the immune response and generating resistance to antibiotics ${ }^{41}$.

Interestingly, it was observed that strains of $E$. coli belonging to a certain pathotype carried genes belonging to other pathotypes. In figure 6, we can observe the distribution of genes in strains isolated from both Mexico City and S.L.P. In addition, these data show that the origin of $E$. coli strains behaves differently when sharing genes between different virotypes, that is, the strains of SLP share genes between different virotypes in relation to $E$. coli strains of the Mexico City. This heterogeneity can be due to the transfer of genetic material that occurs between the bacteria, which can later lead to a new classification of pathotypes.

In the antibiogram tests, resistance, and sensitivity to the antibiotics tested were determined. The results showed a greater number of strains of $E$. coli resistant to different antibiotics in Mexico City compared to strains of $E$. coli from SLP, with a statistically significant difference for AM, cephalothin, SMX/TMP, amoxicillin/clavulanic acid, cefotaxime, and kanamycin. Regarding the percentage of strains resistant to AM, the results coincide with that published by Jiang et al. ${ }^{42}$ Ampicillin as well as CF belong to the group of $\beta$-lactams, the high resistance of the strains against this antibiotic is probably related to the development of $\beta$-lactamases. It has been observed that bacteria that had developed $\beta$-lactamases, also show resistance to amoxicillin and some first-generation cephalosporins, as is the case with $\mathrm{CF}^{43}$.

The results obtained in this work showed a higher percentage of resistance to antibiotics of the strains of E. coli belonging to Mexico City, with respect to the E. coli strains of S.L.P. According to Guan et al. ${ }^{44}$, the resistance can be modified due to geographical location, agricultural management, as well as the levels and 


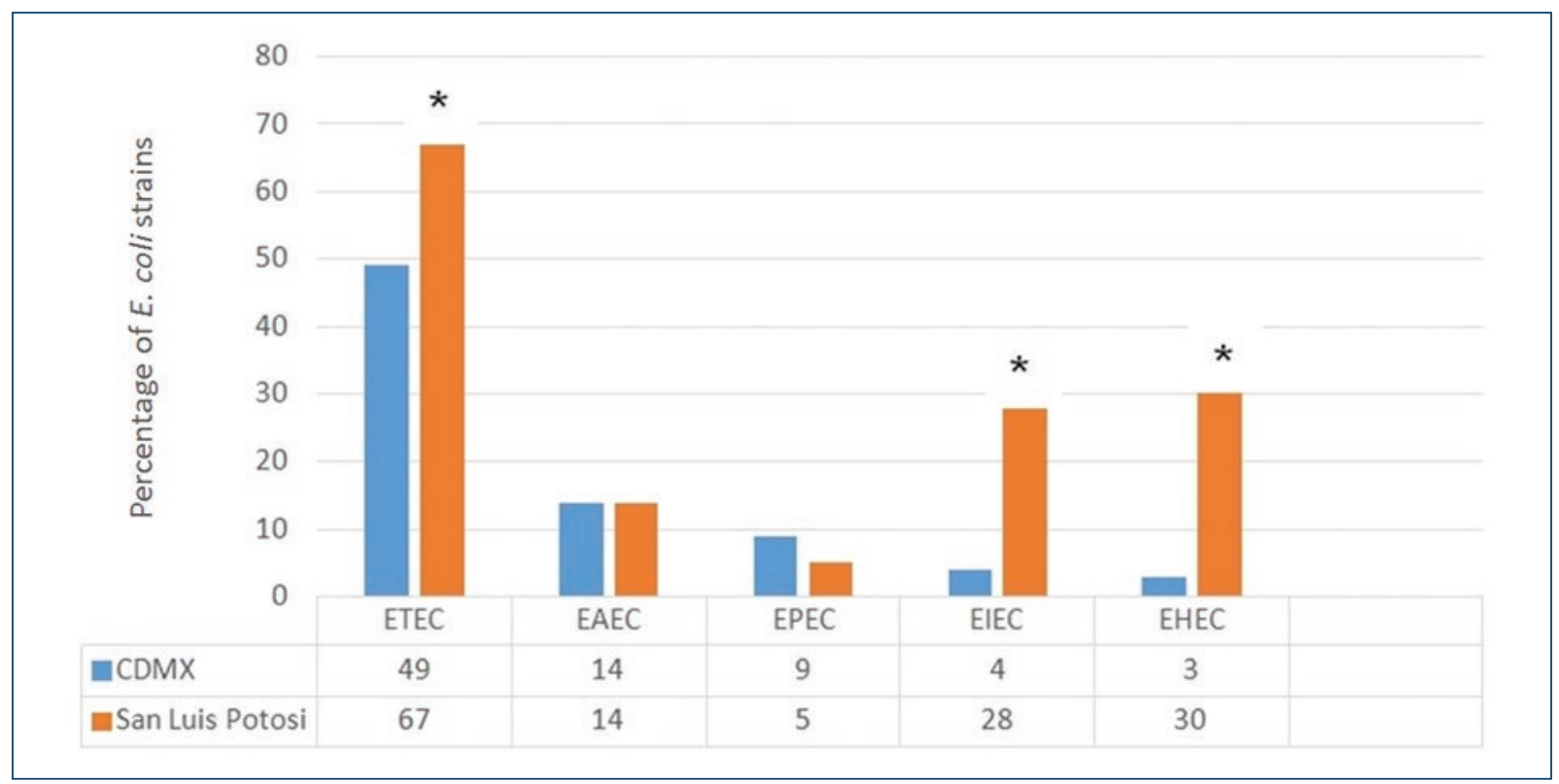

Figure 6. ETEC: enterotoxigenic Escherichia coli; EAEC: enteroaggregative Escherichia coli; EPEC: enteropathogenic Escherichia coli; EIEC: enteroinvasive Escherichia coli; EHEC: enterohemorrhagic Escherichia coli. ${ }^{*} \mathrm{p}<0.00$.

types of antibiotics used in the local population. In relation to the sensitivity to the antimicrobials tested, the highest percentage of sensitive strains occurred in $E$. coli isolated from S.L.P., with statistically significant differences for cefoxitin, SMX/TMP, and amoxicillin/ clavulanic acid. This is probably due to better management of antibiotics in S.L.P.

This is the first comparative study performed with diarrheagenic E. coli in Mexico, with stool samples from the federal entities Mexico City and S.L.P. In these strains, both genotypic and phenotypic aspects of the bacteria were analyzed, showing a high prevalence of the ETEC virotype in both populations. This is in contrast to the EIEC and EHEC virotypes, which showed a high prevalence of $E$. coli strains from SLP, result that is striking since such a high prevalence of these virotypes had not been documented in Mexico. Likewise, a great heterogeneity of genes present in the strains of $E$. coli was observed, since these strains share genes that allow them to be classified in more than one virotype as the strains from S.L.P. being more heterogeneous

Both the biofilm formation and the adhesion to HEp2 cells were presented in greater numbers in strains of S.L.P. All these factors related to the virulence of $E$. coli, allow us to consider that the strains from S.L.P. are more virulent than the strains isolated in the Mexico City.
Regardless of the fact that $E$. coli is one of the most studied bacteria, the present work showed that this bacterium still has a lot of information to contribute.

\section{Conflicts of interest}

The authors declare that they have no conflicts of interests.

\section{Acknowledgments}

We wish to thank Eng. David Limón Cruz for elaborating the figures. This work was supported by Facultad de Medicina, National Autonomous University of Mexico.

\section{Ethical disclosures}

Protection of human and animal subjects. The authors declare that the procedures followed were in accordance with the regulations of the relevant clinical research ethics committee and with those of the Code of Ethics of the World Medical Association (Declaration of Helsinki).

Confidentiality of data. The authors declare that they have followed the protocols of their work center on the publication of patient data. 
Right to privacy and informed consent. The authors declare that no patient data appear in this article.

\section{References}

1. Available from: http://www.who.int/mediacentre/news/releases/2015/foodborne-disease-estimates/es/marzo2017.

2. Available from: http://www.epidemiologia.salud.gob.mx/./morbilidad_nacional.htmIMarzo2011.

3. Paniagua GL, Monroy E, García-González O, Alonso J, Negrete E, Vaca S, et al. Two or more enteropathogens are associated with diarrhoea in mexican children. Ann Clin Microbiol Antimicrob. 2007;6:17.

4. Available from: http://www.slpsalud.gob.mx. [Last accessed on 2014 Jun].

5. Available from: http://www.coneval.gob.mx [Last accessed on $2014 \mathrm{Apr}$ ]

6. Nataro JP, Kaper JB. Diarrheagenic Escherichia coli. Clin Microbiol Rev. 1998;11:142-201.

7. Castro AM. Enfermedades bacterianas del aparato gastrointestinal. In Bacteriología Médica Basada en Problemas. $2^{\text {nd }}$ ed. México: Manual Moderno; 2014. p. 115-43.

8. Savarino SJ, Fasano A, Watson J, Martin BM, Levine MM, Guandalini S, et al. Enteroaggregative Escherichia coli heat-stable enterotoxin 1 represents another subfamily of $E$. coli heat-stable toxin. Proc Natl Acad Sci U S A. 1993;90:3093-7.

9. Nataro JP, Kaper JB, Robins-Browne R, Prado V, Vial P, Levine MM, et al. Patterns of adherence of diarrheagenic Escherichia coli to HEp2 cells. Pediatr Infect Dis J. 1987;6:829-31.

10. Kaper JB, Nataro JP, Mobley HL. Pathogenic Escherichia coli. Nat Rev Microbiol. 2004;2:123-40.

11. Pratt LA, Kolter R. Genetic analysis of Escherichia coli biofilm formation: roles of flagella, motility, chemotaxis and Type I pili. Mol Microbiol. 1998; 30:285-93.

12. Reisner A, Haagensen JA, Schembri MA, Zechner EL, Molin S. Development and maturation of Escherichia coli K-12 biofilms. Mol Microbiol. 2003;48:933-46.

13. Serra DO, Richter AM, Klauck G, Mika F, Hengge R. Microanatomy at cellular resolution and spatial order of physiological differentiation in a bacterial biofilm. MBio. 2013;4:103-13.

14. Christensen GD, Simpson WA, Bisno AL, Beachey EH. Adherence of slime-producing strains of Staphylococcus epidermidis to smooth surfaces. Infect Immun. 1982;37:318-26.

15. Freeman DJ, Falkier FR, Kean CT. New method for detecting slime production by coagulase negative staphylococci to medical devices. J Clin Microbiol. 1985;22:996-1006.

16. Levine MM, Ferreccio C, Prado V, Cayazzo M, Abrego P, Martinez J, et al. Epidemiologic studies of Escherichia coli diarrheal infections in a low socioeconomic level peri-urban community in Santiago, Chile. Am J Epidemiol. 1993:138:849-69.

17. Estrada-García T, Cerna JF, Paheco-Gil L, Velázquez RF, Ochoa TJ, Torres J, et al. Drug-resistant diarrheogenic Escherichia coli, Mexico. Emerg Infect Dis. 2005;11:1306-8.

18. Vidal JA, Canizález-Román A. Patogénesis molecular, epidemiología y diagnóstico de Escherichia coli enteropatógena. Salud Pública Méx. 2007:49:376-85.

19. Sunde M, Fossum K, Solberg A, Sørum H. Antibiotic resistance in Escherichia coli of the normal intestinal flora of swine. Microb Drug Resist. 1998:4:289-99.

20. Bongers $\mathrm{JH}$, Franssen F, Elbers AR, Tielen MJ. Antimicrobial resistance of Escherichia coli isolates from the faecal flora of veterinarians with different professional specialties. Vet Q. 1995;17:146-9.

21. Lim SK, Lee HS, Nam HM, Cho YS, Kim JM, Song SW, et al. Antimicrobial resistance observed in Escherichia coli strains isolated from fecal samples of cattle and pigs in Korea during 2003-2004. Int J Food Microbiol. 2007;116:283-6.

22. Schroeder CM, Meng J, Zhao S, DebRoy C, Torcolini J, Zhao C, et al. Antimicrobial resistance of Escherichia coli O26, 0103, O111, 0128, and 0145 from animals and humans. Emerg Infect Dis. 2002;8:1409-14.
23. Al-Gallas N, Abbassi SM, Hassan AB, Aissa RB. Genotypic and phenotypic profiles of enterotoxigenic Escherichia coli associated with acute diarrhea in Tunis, Tunisia. Curr Microbiol. 2007;55:47-55.

24. Donnenberg MS, Nataro JP. Methods for studying adhesion of diarrheagenic Escherichia coli. Methods Enzymol. 1995;253:324-36.

25. Qadri F, Svennerholm AM, Faruque AS, Sack RB. Enterotoxigenic Escherichia coli in developing countries: epidemiology, microbiology, clinical features, treatment, and prevention. Clin Microbiol Rev. 2005; 18:465-83.

26. Cortes OA, Rodriguez AG, Moreno E, et al. Brote causado por Escherichia coli en Chalco, México. Salud Publica Mex. 2002;44:297-302.

27. Jiang ZD, Mathewson JJ, Ericsson CD, Svennerholm AM, Pulido C, DuPont HL, et al. Characterization of enterotoxigenic Escherichia coli strains in patients with travelers' diarrhea acquired in Guadalajara, Mexico, 1992-1997. J Infect Dis. 2000;181:779-82.

28. Estrada-Garcia T, Lopez-Saucedo C, Thompson-Bonilla R, Abonce M, Lopez-Hernandez D, Santos JI, et al. Association of diarrheagenic Escherichia coli pathotypes with infection and diarrhea among Mexican children and association of atypical enteropathogenic $E$. coli with acute diarrhea. J Clin Microbiol. 2009;47:93-8.

29. Vilchez S, Reyes D, Paniagua M, Bucardo F, Möllby R, Weintraub A, et al. Prevalence of diarrhoeagenic Escherichia coli in children from León, Nicaragua. J Med Microbiol. 2009;58:630-7.

30. Clarke SC, Haigh RD, Freestone PP, Williams PH. Virulence of enteropathogenic Escherichia coli, a global pathogen. Clin Microbiol Rev. 2003;16:365-78

31. Available from: http://www.who.int/es. [Last accessed on 2012 May].

32. Escher M, Scavia G, Morabito S, Tozzoli R, Maugliani A, Cantoni S, et al. A severe foodborne outbreak of diarrhoea linked to a canteen in Italy caused by enteroinvasive Escherichia coli, an uncommon agent. Epidemiol Infect. 2014;142:2559-66.

33. Ochoa TJ, Barletta F, Contreras C, Mercado E. New insights into the epidemiology of enteropathogenic Escherichia coli infection. Trans R Soc Trop Med Hyg. 2008;102:852-6.

34. Ochoa TJ, Mercado EH, Durand D, Rivera FP, Mosquito S, Contreras C et al. Frecuencia y patotipos de Escherichia coli diarrogénica en niños peruanos con y sin diarrea. Rev Peru Med Exp Salud Pública. 2011; 28:13-20.

35. Aslani MM, Alikhani MY, Zavari A, Yousefi R, Zamani AR. Characterization of enteroaggregative Escherichia coli (EAEC) clinical isolates and their antibiotic resistance pattern. Int J Infect Dis. 2011;15:e136-9.

36. Jenkins C, Tembo M, Chart H, Cheasty T, Willshaw GA, Phillips AD, et al. Detection of enteroaggregative Escherichia coli in faecal samples from patients in the community with diarrhoea. J Med Microbiol. 2006:55:1493-7.

37. Weintraub A. Enteroaggregative Escherichia coli: epidemiology, virulence and detection. J Med Microbiol. 2007;56:4-8.

38. Wood TK, González Barrios AF, Herzberg M, Lee J. Motility influences biofilm architecture in Escherichia coli. Appl Microbiol Biotechnol. 2006; 72:361-7.

39. Uhlich GA, Chen CY, Cottrell BJ, Nguyen LH. Growth media and temperature effects on biofilm formation by serotype 0157:H7 and non-O157 Shiga toxin-producing Escherichia coli. FEMS Microbiol Lett. 2014; 354:133-41

40. Soto SM, Smithson A, Martinez JA, Horcajada JP, Mensa J, Vila J, et al. Biofilm formation in uropathogenic Escherichia coli strains: relationship with prostatitis, urovirulence factors and antimicrobial resistance. J Urol. 2007;177:365-8.

41. Tyerman JG, Ponciano JM, Joyce P, Forney LJ, Harmon LJ. The evolution of antibiotic susceptibility and resistance during the formation of Escherichia coli biofilms in the absence of antibiotics. BMC Evol Biol. 2013;13:22.

42. Jiang ZD, Ke S, Palazzini E, Riopel L, Dupont H. In vitro activity and fecal concentration of rifaximin after oral administration. Antimicrob Agents Chemother. 2000;44:2205-6.

43. Karami N, Hannoun $\mathrm{C}$, Adlerberth I, Wold AE. Colonization dynamics of ampicillin-resistant Escherichia coli in the infantile colonic microbiota. J Antimicrob Chemother. 2008;62:703-8.

44. Guan S, Xu R, Chen S, Odumeru J, Gyles C. Development of a procedure for discriminating among Escherichia coli isolates from animal and human sources. Appl Environ Microbiol. 2002;68:2690-8. 